Author's Conrtibution

A - Study Design

B - Data Collection

C - Statistical Analysis

D - Data Interpretation

E - Manuscript Preparation

$\mathrm{F}$ - Literature Search

$\mathrm{G}$ - Funds Collection

\title{
The Contest Effectiveness of the Men's National Judo Team of Japan and Character of Their Technical-Tactical Preparation during the World Judo Championships 2010
}

\author{
Marek Adam ${ }^{1(A, B, C, D, F)}$, Sławomir Tyszkowski ${ }^{1(A, B, C, D, E, F, G)}$, \\ Mirosław Smaruji(A,B,C,F) \\ 1 Jedrzej Sniadecki Academy of Physical Education and Sport in Gdansk, \\ Poland, Department of Martial Arts \\ ${ }^{2}$ Jedrzej Sniadecki Academy of Physical Education and Sport in Gdansk, \\ Poland, Department of the Theory of Sport and Human Motorics
}

Key words: judo, indices, technique, tactics

\section{Abstract}

Background: The aim of our research was to determine the contest effectiveness of Japanese judo competitors and to state the quantitative an qualitative indices of the tactical-technical preparation (PTT). The values of these indices may be used for controlling the process of special preparation.

Materials and methods:

Medal classification of the national teams from all Olympic Games and World Championships, and contest effectiveness of the national teams during 2007-2010 were determined. The analysis of PTT indices of 16 Japanese competitors was carried out. They fought 78 contests during the World Championships 2010. Predominant techniques were described. The selected indices have been assessed.

Results: Japanese competitors prevailed over their opponents in the men's group during the Olympic Games and the World Championships. After changing sport rules in judo, they overcame their poor performance within 2007-2009, and they have become leaders in world's judo. Japanese competitors are highly effective in leg throws, especially in such throws as: uchimata, osoto gari, and kouchi gari as well as seoi nage (although this throw is a hand technique). They executed throws forwards and mainly by means of pivot. Japanese competitors had a positive value of activity indices and high indices of defense.

Conclusions: Sport results achieved by Japanese judo competitors prove their high contest performance and the dominating position in judo competitions. Among their dominating techniques, we can see leg techniques performed by pivoting and breaking balance forwards on toes. They are also effective in executing grappling techniques such as holdings (immobilizations) for example. During the World Championships in 2010 Japanese competitors were characterized by a positive value of activity indices and high indices of defence.

$\begin{array}{lrlr}\text { Word count: } & 3176 & & \\ \text { Tables: } & 5 & \text { Received: } & \text { January } 2011 \\ \text { Figures: } & 7 & \text { Accepted: } & \text { March } 2011 \\ \text { References: } & 16 & \text { Published: } & \text { March } 2011\end{array}$

Address for correspondence

Dr Marek Adam, Academy of Physical Education and Sport Dep. Of Martial Arts,

80-336 Gdańsk, Poland, ul. K. Górskiego 1, Phone: +4858 554-71-72, e-mail: awfadammarek@wp.pl 


\section{Introduction}

Judo, or the Way by Gentleness, an ideal of physical exercise and a reliable system of selfdefense, was specially created from traditional Japanese martial arts [1]. In 1882 Kano Jigoro founded the Kodokan to teach judo to others. Within a few years, the number of students rapidly increased. They came from all over Japan, many having left jujutsu to train with Kano Jigoro. Eventually, judo displaced jujutsu in Japan, and no one any longer speaks of jujutsu as a contemporary art in Japan, although the word has survived overseas [1].

For many years Japanese judo teachers have created forms and methods of judo training, based on the principle of maximum efficiency in the techniques of attack and defense [1]. Although Japanese judokas are always well prepared technically for a competition, in many world championships and Olympic Games they lost to players from Europe, America and Asia. During the 3rd World Championships in Paris (open weight category only), a Dutchman Anton Geesink defeated Koji Sone - a World and Japan champion. That defeat was a sensation, because it overturned the view that Japanese competitors cannot be defeated in a judo contest. Additionally, that event resulted in introduction of weight categories in judo in Olympic Games and world championships. Japanese competitors dominated in many judo tournaments, but many competitors from other countries emerged and they also achieved the titles of world and Olympic champions (Ruska, Totikashvili, Rodrigez, Seisenbacher, Aurelio, Kovac, Legien, Nastula, Kubacki, and others). During the World Championships in Brazil in 2007, the Japanese won only two medals (the bronze in under $73 \mathrm{~kg}$ category, and the gold in the open category). That result was a defeat for Japan's judokas, and they were ranked at the $6^{\text {th }}$ position. When the World Championships in the open category were organized in France in 2008, all the Japanese competitors were knocked out just in the first elimination contest. The same situation occurred in Rotterdam in 2009 during the World Championships when the Japanese won two medals only (the silver under $60 \mathrm{~kg}$ and the bronze under $100 \mathrm{~kg}$ ) and reached the $9^{\text {th }}$ position, the worst result in world championships contests they have ever participated. In 2009 during team world championships Japan's judo team secured their $5^{\text {th }}$ position, behind the teams from Georgia, Uzbekistan, Russia and Brazil. In 2010 new rules were introduced which prohibited competitors from direct grasping opponent's legs. Such throws are only allowed in form of counterattack and combinations. Those changes were aimed at reducing the number of the competitors who executed techniques which are originated beyond the accepted judo throws classification. The changes were also to "upright" the postures of competitors who cannot grasp opponent's legs ${ }^{1}$. During the World Championships in Tokyo in 2010, the Japanese men's judo team won nine medals, including four gold ones; they outdistanced the other teams and got the $1^{\text {st }}$ rank. In this year the Japanese defeated the national team of Brazil in the final contest during World Judo Championships.

In this paper we have presented all the sport results which Japanese men's teams achieved in recent six competitions in the Olympic Games and the World Championships. The dominant techniques have been determined as well as the values of the indices of technical-tactical preparation of the Japanese competitors, which they got during the World Championships in 2010.

The aim of our research was to determine the contest effectiveness of Japanese judo competitors and to state the quantitative an qualitative indices of the tactical-technical preparation (PTT). The values of these indices may be used for controlling the process of special preparation.

\section{Material and Methods}

Medal classifications of the Olympic Games (1964-2008) and the World Championships (1956-2010) of the best men's teams have been carried out. The assessment of the contest effectiveness of the national teams within 2007-2010 was also presented. That effectiveness was determined by three criteria, namely: the values of won medals, the total sum of points scored according to taken places $\left(1^{\text {st }}\right.$ place $-9,2^{\text {nd }}$ place $-5,3^{\text {rd }}$ place $-3,5^{\text {th }}$ place -1$)$, the number of points per one competitor.

${ }^{1}$ Cf. http://www.ijf.org/ and http://www.eju.net/ 
During the World Championships in 2010, 78 contests fought by 16 Japanese were recorded. The contests were recorded by means of standard audio-video equipment. The film material was graphically processed in order to determine the features of technical-tactical preparation [2]. The Japanese competitors' dominant techniques were determined by three criteria: the number of attacks performed by ippon, the number of all effective attacks, and points scored in one contest. The effectiveness of group techniques and ways of performing throws (forwards, backwards, pivot, without pivot) were shown by scored points in one contest (Sa). The values of indices of activity and effectiveness (both in attack and defense) characteristic of the Japanese were carried out (So).

Determining the contest effectiveness as well as the dominant techniques the following formula has been used:

$\mathrm{K}=\mathrm{K} 1+\mathrm{K} 2+\mathrm{K} 3$

where:

$K$ - final classification,

$K 1$ - according to the first criterion classification

$K 2$ - according to the second criterion classification

$\mathrm{K} 3$ - according to the third criterion classification

If we have the same $\mathrm{K} 1+\mathrm{K} 2+\mathrm{K} 3$ sum of points, consecutive places will be determined by a higher place in $\mathrm{K} 1$ ranking, then $\mathrm{K} 2$ and $\mathrm{K} 3$ finally.

\section{Estimation of the activity indices}

Activity is one of the analyzed parameters which allows finding differences in the frequency of attacks performed by a competitor and his opponents. The value of this index should relate to the competitor's efficiency and his physical preparation. The activity index can be determined by the following formula:

$\mathrm{Aa}=\operatorname{sum}$ of $\mathrm{A} / \mathrm{n}$

Ao $=$ sum of $a / n$

$\mathrm{A}=\mathrm{Aa}-\mathrm{Ao}$

where:

Aa - activity of attack

A sum - the number of recorded attacks of competitor

$n$ - the number of analyzed contests

Ao - activity of defense

a sum - the number of recorded opponents' attacks

$A-$ activity index

\section{Estimation of the effectiveness indices}

The frequency of effectively performed techniques can be assessed by using consecutive PTT coefficients. Effectiveness of attack and effectiveness of defense, it is a proportion between attempt and successful attacks. The values of these parameters can be determined by analyzing the attack and defense activities, following the formulas:

$E a=A S$ sum / AP sum (x 100\%) 
where:

Ea - effectiveness of attack

AS sum - sum of effective attacks

AP sum - sum of all attacks performed by the examined competitors

and:

Eo $=1(100 \%)-$ As sum / Ap sum $(x 100 \%)$

where:

Eo - effectiveness of defense

$1(100 \%)$ - the value of defense prior to contests

As sum - sum of effective attacks, performed by the examined competitors' opponents

Ap sum - sum of all attacks, performed by the examined competitors' opponents.

The effectiveness of the classifications of judo techniques groups was shown by average scores obtained in one contest (Sa).

The effectiveness indices can be determined by analyzing referee judgments (scored points) of efficiently executed techniques and points lost (opponents efficient attacks) calculated per one contest. We calculate it as follows:

$S a=5 \times M+7 \times M+10 \times M / n$

where:

Sa - attack efficiency index

5, 7, 10 - scored points at efficient attacks (yuko, waza ari, ippon)

$M-$ number of effective attacks, performed by the examined judokas

$n-$ number of the analyzed contest

So - defense efficiency index (opponents' efficiency attack)

$m-$ number of effective attacks, performed by the opponents

$S-$ efficiency index (final efficiency)

Names, classification and spelling have been given in accordance with the Kodokan dictionary [3].

\section{Results}

The number of medals won by Japanese competitors during the Olympic Games and the World Championships gives them the first place among the national teams participating in those tournaments. The sequence of the first five teams is the same both in the Olympic Games and in the World Championships. Korea, France, Holland are among the best men's judo teams and Poland's team also takes high position (Tables 1 and 2).

In recent years, after the collapse of the USSR, new teams such as Georgia, Russia, Uzbekistan, Ukraine, Azerbaijan and others have also played a important role in judo competitions (Table 3).

During the Olympic Games Japan's national team won twice more gold medals than Korea's and France's teams altogether. Poland's team got the 6th place; they won the last medal during the 1996 Olympic Games (Table 1).

During the World Championships Japan's competitors won over twice more gold medals than competitors from Korea and France. Poland's team took the $9^{\text {th }}$ place (Table 2).

During the World Championships in Rio de Janeiro in 2007 Japan's national teams lost competitions; they won only two medals, one gold and one bronze, and were classified at the $6^{\text {th }}$ posi- 
tion; while Brazil's national team won 3 gold medals and one bronze medal. During the Olympic Games in Beijing in 2008 Japanese competitors kept their $1^{\text {st }}$ place, and with two gold medals they prevailed over Korea's team, which won one gold and two silver medals. In 2008 in Levallois - France, the World Championships were played in the open category, all the Japanese competitors lost their contests in the eliminations. During, next championships held in Rotterdam in 2009, the Japanese won two medals: one silver and one bronze, and they were classified at the $9^{\text {th }}$ place. It was the worst result of Japanese judo competitors during all Olympic games and world championships tournaments.

Following the most important changes in judo sport rules in 2010, Japan's team was the best one. Japanese competitors are very effective and have high frequency in attempting throws. The most effective leg throws were as follows: uchimata, osoto gari, kouchi gari, ashi guruma, sasae tsurikomi ashi. They also often attempted: Deashi barai, ouchi gari and kosoto gari. Seoi nage and tai otoshi were the hand throws which were also often attempted by the Japanese. Japanese judo players also effectively executed harai goshi and sode tsurikomi goshi, the throws from the hip group throws (Figures 1-2, Table 4). They highly prevailed over their opponents in grappling techniques as some immobilization techniques: kesa gatame and kuzure kami shiho gatame (Figures 1-3, Table 4). They effectively perform the forwards throws by pivoting and breaking opponent's balance to the front direction (Figures 4-5). The Japanese judokas' opponents performed throwing techniques less effectively, but at executing sutemi waza, they were more effective with throws as: tani otoshi and uki waza. They also presented high effectiveness performing hand throws such as seoi nage and a remarkable number of attempts with seoi nage (Figure 2, Table 4). The throws without pivoting (Figure 4) were among the most effective ones. They often

Tab. 1. Medal ranking of men's teams at the Olympic Games 1964-2008

\begin{tabular}{|c|c|c|c|c|c|}
\hline Place & Teams & Gold medals & Silver medals & Bronze medals & Total medals \\
\hline $\mathbf{1}$ & Japan & $\mathbf{2 6}$ & $\mathbf{7}$ & $\mathbf{8}$ & $\mathbf{4 1}$ \\
\hline 2 & Korea & 7 & 12 & 9 & 28 \\
\hline 3 & France & 6 & 5 & 15 & 26 \\
\hline 4 & USSR & 5 & 5 & 13 & 23 \\
\hline 5 & Holland & 4 & 0 & 8 & 12 \\
\hline $\mathbf{6}$ & Poland & $\mathbf{3}$ & $\mathbf{2}$ & $\mathbf{2}$ & $\mathbf{7}$ \\
\hline
\end{tabular}

Tab. 2. Medal ranking of men's teams in the World Championships 1956-2010

\begin{tabular}{|c|c|c|c|c|c|}
\hline Place & Teams & Gold medals & Silver medals & Bronze medals & Total medals \\
\hline $\mathbf{1}$ & Japan & $\mathbf{8 0}$ & $\mathbf{4 3}$ & $\mathbf{4 4}$ & $\mathbf{1 6 7}$ \\
\hline $\mathbf{2}$ & Korea & 19 & 7 & 29 & 55 \\
\hline 3 & France & 16 & 15 & 20 & 51 \\
\hline 4 & USSR & 11 & 12 & 33 & 56 \\
\hline 5 & Holland & 7 & 9 & 12 & 28 \\
\hline $\mathbf{9}$ & Poland & $\mathbf{4}$ & $\mathbf{2}$ & $\mathbf{1 4}$ & $\mathbf{2 0}$ \\
\hline
\end{tabular}

* competitors from the USSR (the Union of Soviet Socialist Republics) took part in the above said tournaments in 1964-1991

Tab. 3. Contest effectiveness of the men's teams in the World Championships and the Olympic Games in 2007-2010

\begin{tabular}{|c|c|c|c|c|c|}
\hline Position (K) & 1 & 2 & 3 & 4 & 5 \\
\hline K1-K2-K3 & $1-1-1$ & $2-2-2$ & $2-3-3$ & $4-4-4$ & $4-4-5$ \\
\hline World Championships 2007 & BRA & GEO & FRA & NED & JPN \\
\hline Position (K) & 1 & 2 & 3 & 4 & 5 \\
\hline K1-K2-K3 & $2-1-3$ & $1-2-4$ & $3-3-5$ & $4-4-8$ & $4-5-8$ \\
\hline Olympic Games 2008 & KOR & JPN & AZE & GEO & MGL \\
\hline Position (K) & 1 & 2 & 3 & 4 & 4 \\
\hline K1-K2-K3 & $1-1-3$ & $2-2-1$ & $3-3-2$ & $4-4-4$ & $4-4-4$ \\
\hline World Open Championships 2008 & FRA & RUS & POL & NED & HUN \\
\hline Position (K) & 1 & 2 & 3 & 3 & $5-5$ \\
\hline K1-K2-K3 & $1-1-1$ & $2-2-2$ & $3-3-4$ & $3-3-4$ & $3-5-6$ \\
\hline World Championships 2009 & KOR & RUS & UKR & KAZ & MGL-FRA \\
\hline Position (K) & 1 & 2 & 3 & 4 & 5 \\
\hline K1-K2-K3 & $1-1-1$ & $2-2-4$ & $4-3-6$ & $4-7-2$ & $3-4-7$ \\
\hline World Championships 2010 & JPN & FRA & UZB & GRE & KOR \\
\hline
\end{tabular}


attempted leg throws such as kouchi gari, uchimata, deashi barai but with little effect. As for grappling techniques, Japanese competitors' opponents often surprised them by performing kansetsu waza (Figure 3).

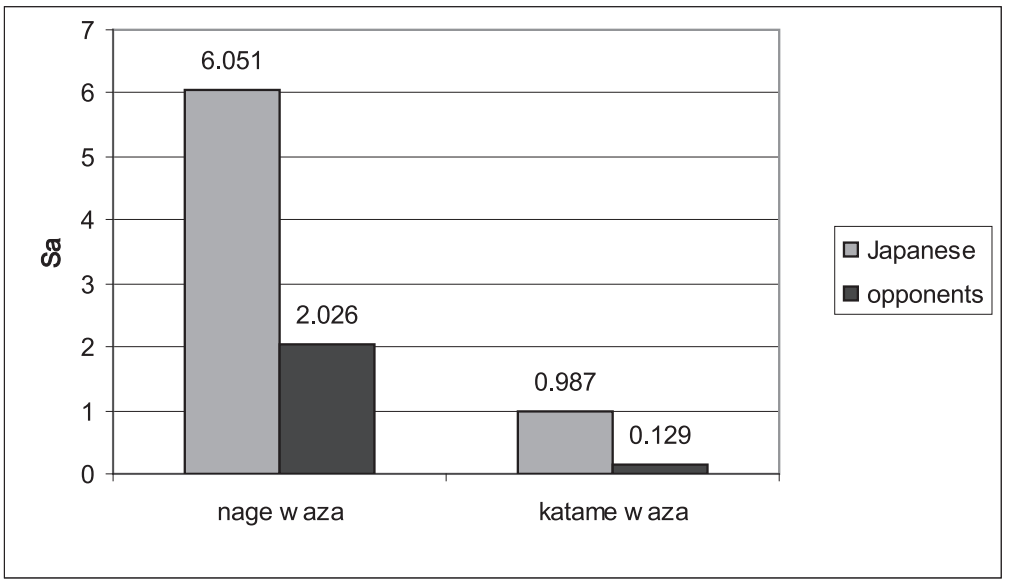

Fig. 1. Efficiency of throws and grappling techniques of Japan's judokas and their opponents

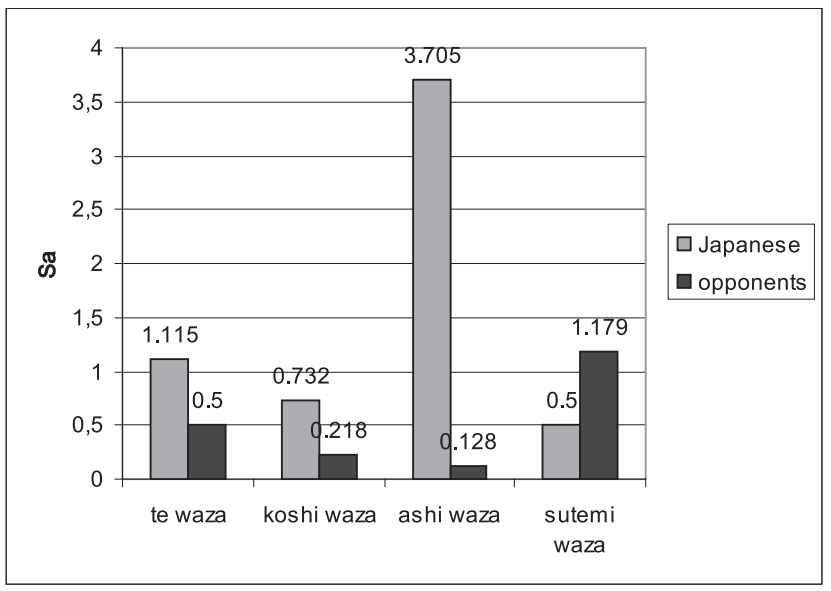

Fig. 2. Efficiency of throws of Japan's judokas and their opponents

Tab. 4. Techniques performed by Japanese competitors during the World Championships in Tokyo 2010

\begin{tabular}{|c|c|c|c|c|c|c|}
\hline Position (K) & K1 & K2 & K3 & Dominant techniques & The techniques most often performed & $\begin{array}{c}\text { Number } \\
\text { of attacks }\end{array}$ \\
\hline $\mathbf{1}$ & 1 & 1 & 1 & Uchimata & Uchimata & $\mathbf{1 2 4}$ \\
\hline $\mathbf{2}$ & 1 & 3 & 3 & Osoto gari & Deashi barai & $\mathbf{9 6}$ \\
\hline $\mathbf{3}$ & 3 & 2 & 2 & Seoi nage & Kouchi gari & $\mathbf{8 5}$ \\
\hline $\mathbf{4}$ & 4 & 4 & 4 & Kouchi gari & Ouchi gari & $\mathbf{5 7}$ \\
\hline $\mathbf{5}$ & 4 & 5 & 5 & Harai goshi & Otoshi & $\mathbf{5 3}$ \\
\hline $\mathbf{6}$ & 6 & 6 & 6 & Kesa gatame & Kosoto gari & $\mathbf{4 1}$ \\
\hline $\mathbf{7}$ & 6 & 8 & 7 & Kami shiho gatame & Soto makikomi & $\mathbf{3 3}$ \\
\hline $\mathbf{7}$ & 6 & 8 & 7 & Ashi guruma & Harai goshi & $\mathbf{3 2}$ \\
\hline $\mathbf{9}$ & 9 & 8 & 9 & Sasae tsurikomi ashi & Sode tsurikomi goshi & \\
\hline $\mathbf{1 0}$ & 9 & 8 & 10 & & &
\end{tabular}

Tab. 5. Techniques performed by the opponents of Japanese competitors during the World Championships in 2010

\begin{tabular}{|c|c|c|c|c|c|c|}
\hline Position $(\mathrm{K})$ & $\mathrm{K} 1$ & $\mathrm{~K} 2$ & $\mathrm{~K} 3$ & Dominant techniques & $\begin{array}{c}\text { The techniques most often } \\
\text { performed }\end{array}$ & $\begin{array}{c}\text { Number of } \\
\text { attacks }\end{array}$ \\
\hline $\mathbf{1}$ & 1 & 1 & 1 & Tani otoshi & Kouchi gari & $\mathbf{9 0}$ \\
\hline $\mathbf{2}$ & 2 & 2 & 2 & Uki waza & Uchimata & $\mathbf{8 7}$ \\
\hline $\mathbf{3}$ & 3 & 3 & 3 & Seoi nage & Deashi barai & $\mathbf{7 0}$ \\
\hline $\mathbf{4}$ & $\mathbf{4}$ & 4 & $\mathbf{4}$ & Harai goshi & Seoi nage & $\mathbf{7 0}$ \\
\hline
\end{tabular}


Japan's competitors had positive indices of activity, prevailing over their opponents in the frequency of attacks $A=+0.82$ (Figure 6 ). They also had higher effectiveness in attack and in defense. The values of those indices were $\mathrm{Ea}=8.4 \%$ and $\mathrm{Eo}=97 \%$ respectively (Figure 7 ).

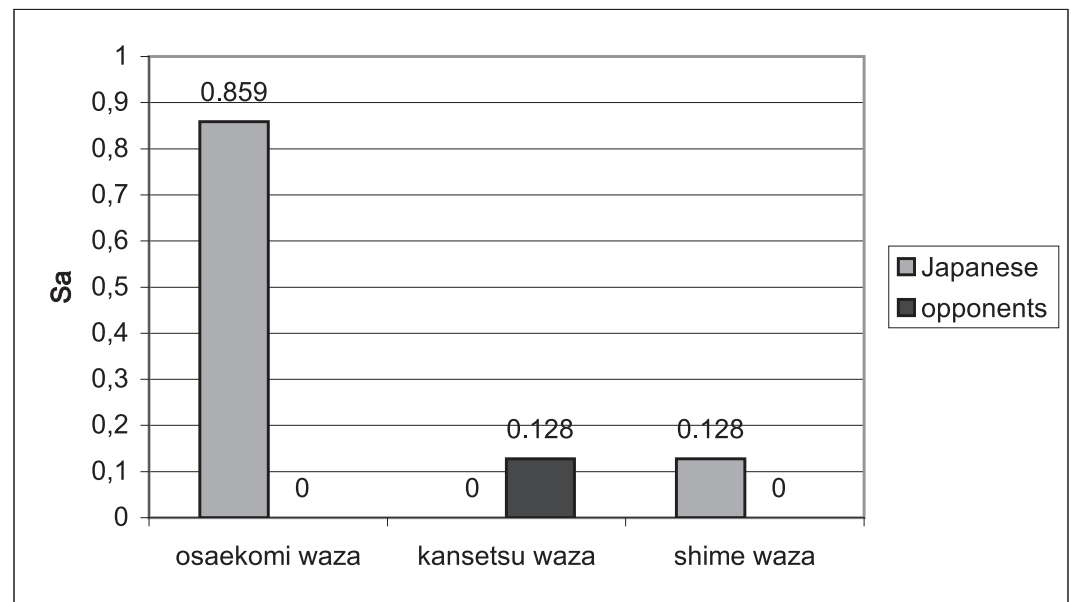

Fig. 3. Efficiency of grappling techniques of Japan's judokas and their opponents

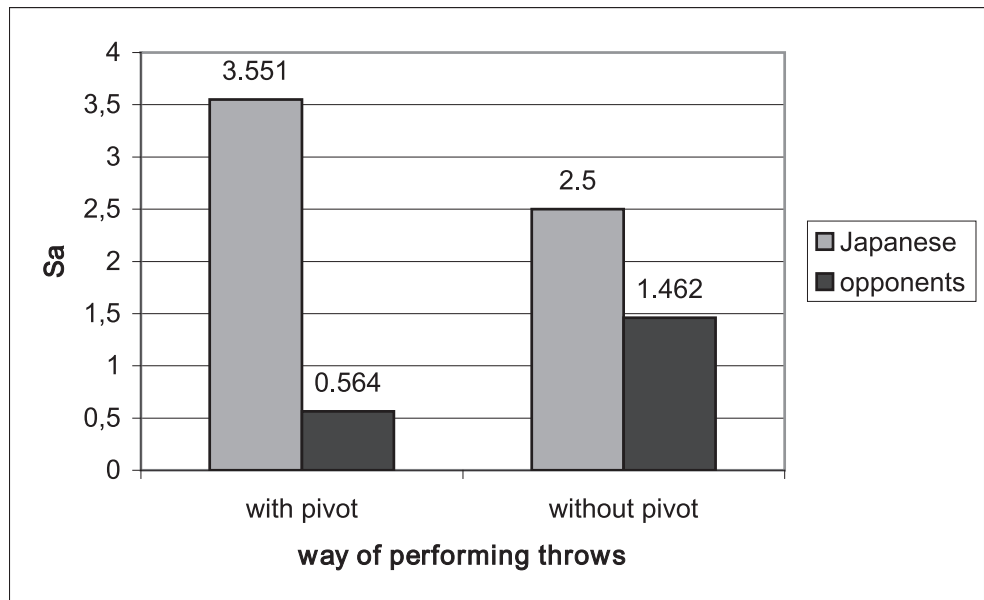

Fig. 4. Throws performed with and without body pivots by Japan's judokas and their opponents

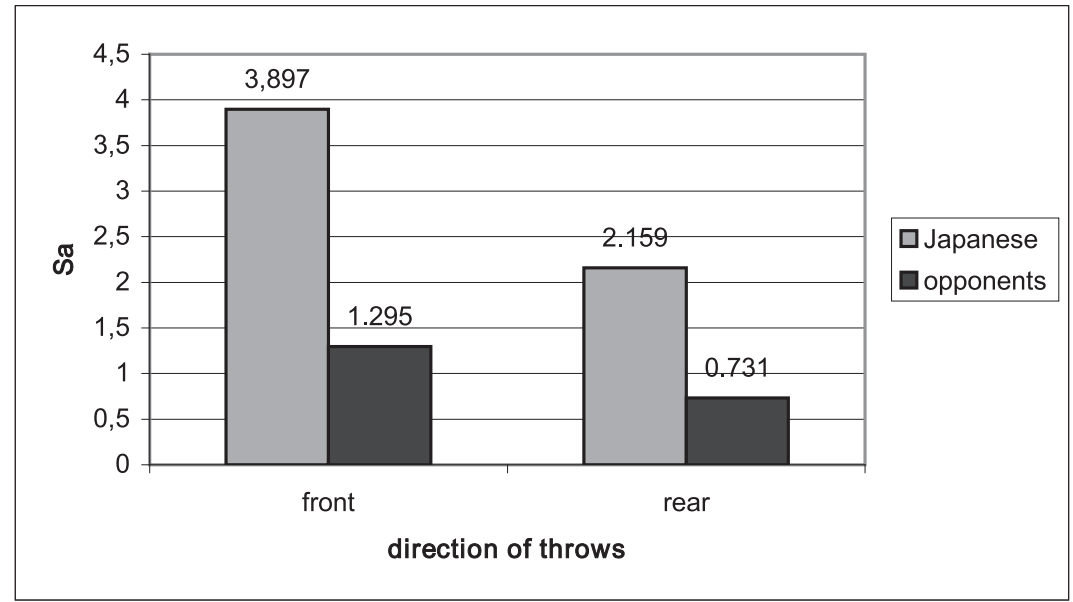

Fig. 5. Throws performed with breaking balance to the front and rear directions by the Japan's judokas and their opponents 


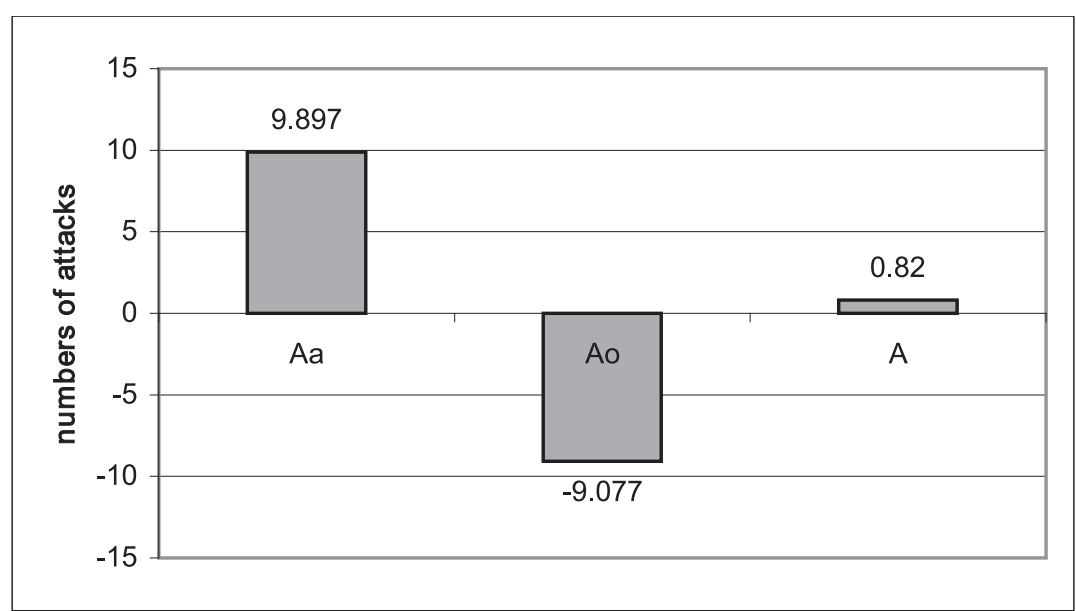

Fig. 6. Numbers of attacks attempted per one contest by Japanese judokas and their opponents

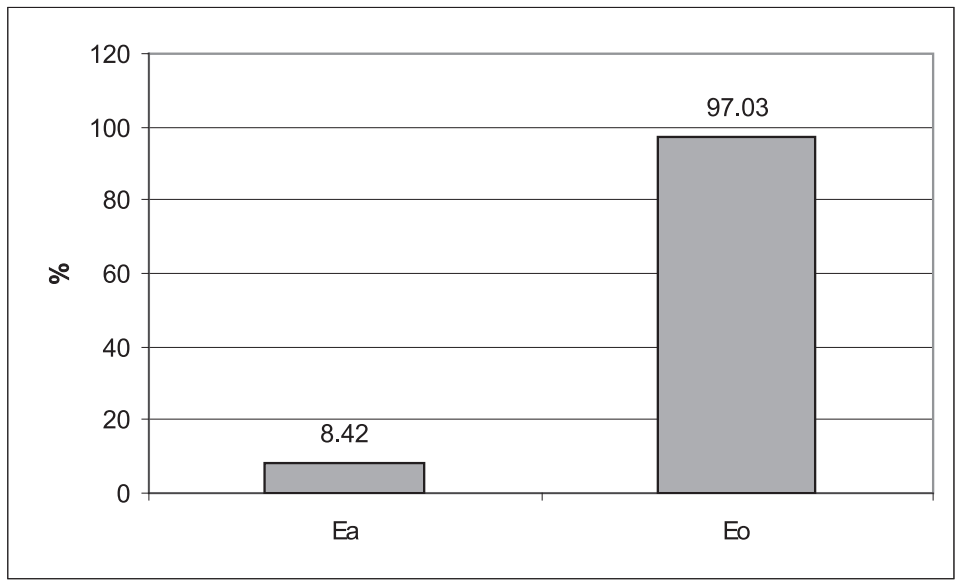

Fig. 7. Effectiveness of attacks and defense of the Japan's judokas

\section{Discussion}

The Japanese national judo team is an unquestionable leader among world judo teams, and their number of medals is remarkably higher than that of other teams, such as Korea, France, Brazil and Holland (Tables 1-2). In the past three years (2007-2009) the Japanese had lower sport results. However, after the introduction of new judo sport rules in 2010, Japanese male competitors regained their leading position (Table 3 ). The Japanese competitors prevail over their opponents, performing leg throws and grappling techniques (immobilizations) (Figures $1-3$ ). They perform throws by pivoting and breaking opponents' balance to the front (Figures 4-5). Their opponents performed sutemi throws with high effectiveness ("sacrifice" throws) (Figures 2, 4). Japanese competitors also had a higher frequency of attacks and higher effectiveness both in attack and in defense (Figure 6-7). The value of those indices allows saying that every twelfth attack was successful, and their opponents had every thirty-third attack successful. One should consider that koka was cancelled in 2009 , which may have resulted in decreasing the frequency of performing effective attacks and decreasing the value of the Ea index $[4,5,6]$. Observations and analyses of technical-tactical preparations of Japanese judokas have been carried out since the beginning of judo competitions. Otaki [7] carried out the observations of Japanese judokas' contests within 1929-1952, and he stated that majority of the contests were won by throws $-79.3 \%$, and by grappling techniques $-20.7 \%$. In the group by throws the most effective were the following throws: ashi waza $54.2 \%$, koshi waza $27.1 \%$, te waza $16.2 \%$ and sutemi waza $2.5 \%$. Uchimata, osoto gari, harai goshi and seoi nage were dominant techniques 
within the group of throws, while within the grapplings osaekomi waza was the most effective technique $(67.2 \%)$, then shime waza $23.1 \%$ and kansetsu waza $9.7 \%$. The observations of the Japanese judokas by Thibault [8], between 1956-1960, manifested similar proportions: throws $77.8 \%$, grapplings $22.2 \%$; ashi waza $53 \%$, koshi waza $23.4 \%$, te waza $18.1 \%$ and sutemi waza $5.5 \%$. Uchimata, osoto gari, seoi nage, tsurikomi goshi and harai goshi were the most effective throws. Among grapplings the most effective were: osaekomi waza $77.4 \%$ then shime waza $17.9 \%$ and kansetsu waza $4.7 \%$. Contemporary judo competitions are analyzed by Japanese researchers [9-12]. Many competitors from the former USSR countries, Georgia, Russia, Uzbekistan, Ukraine, Kazakhstan, Estonia, Lithuania and Latvia, also successfully take part in judo competitions, and they win medals in the Olympic Games and the world championships. In those countries there are some types of national combat sports, which have been the source of techniques introduced to judo [13]. Various ways of grasping the opponent's legs were among those techniques. Those techniques, often executed in judo contests, affected the character of judo combat which became similar to free-style wrestling combat. Also competitors' standing postures are strongly bent forwards in order to have an opportunity to grasp legs.

As already said in this paper, some important changes were introduced to judo sport rules in 2009 and 2010. Previously (before 2009) competitors with poor technique but physically welltrained and with some experience of other combat styles could successfully compete in judo tournaments $[14]^{2}$. Japan's judo competitors presented the return to "the traditional judo style" of judo contest - without grasping legs - in the first prestigious tournament of the World Championships in 2010.

According to Tomiki [15], results in judo have three basic and objective factors: elasticity and muscular flexibility, static force and dynamic and efficient nervous-muscle layout. All the Japanese judokas have manifested the said factors. Excellent technical preparation of the Japanese judokas, manifests itself by economically performed judo techniques during contests. Japanese judokas can be overcome with excellent physical preparation, aiming for a good technical and tactical preparation [16].

\section{Conclusions}

Men's judo competitors from Japan are unquestionable leaders in the world judo. Other competitors are joining the traditionally strong judo teams from Korea, France and Holland. These are men's judo teams from the former USSR countries: Georgia, Russia, Uzbekistan, Ukraine and Azerbaijan. Within the period of 2007-2009 Japan's team had poor judo performance; but following the new rules they regained their leading position in world's judo. During the World Championships in 2010, the Japanese competitors prevailed over their opponents in effective performance of leg, hand and hip throws as well as immobilizations and strangling techniques. The most often performed throws were those by pivoting a body and breaking the opponent's balance forwards onto the toes. The most effective throws were as follows: uchimata, seoi nage, osoto gari, kouchi gari and harai goshi. Among grappling techniques: kesa gatame and kuzure kami shiho game were used with great success. The opponents performed effectively so called "sacrifice" throws as: tani otoshi, uki waza, tomoe nage, harai makikomi, ura nage and armlocks - juji gatame. During the World Championships in 2010 Japanese competitors had a higher frequency of attacks than their opponents and a high index of defense.

\section{References}

1. Kano J. Kodokan Judo. Edited under the supervision of the Kodokan Editorial Committee. Tokyo, New York, London: Kodansha International; 1994.

2. Adam M, Smaruj M, Laskowski R. Graficzna metoda rejestracji walki judo [in Polish] [The graphic method of recording a judo contest]. Sport Wyczynowy 2005;5-6:33-43.

${ }^{2}$ Cf. http://www.ijf.org/ and http://www.eju.net/ 
3. Kawamura T, Daigo T. Kodokan New Japanese-English Dictionary of Judo. Tokyo: The Foundation of Kodokan Judo Institute; 2000.

4. Łaksa C. Wyniki analizy obserwacji przy pomocy współczynnika aktywności i skuteczności walki w wadze lekkiej podczas Mistrzostw Europy seniorów w 1971 roku [in Polish] [Results of an analysis of observation by means of activity coefficient and the effectiveness of combat in the lightweight category during seniors' European Championships in 1971]. Biblioteka Trenera 1972;4:21-38.

5. Laskowski R, Smaruj M, Adam M. Charakterystyka przygotowania techniczno taktycznego w judo kobiet na podstawie obserwacji Ogólnopolskich Turniejów Klasyfikacyjnych w 2003 roku [in Polish] [A characteristic of technical-tactical preparation in women's judo on the basis of observations of Polish Classifying Tournaments in 2003]. In: Kuder A, Perkowski K, Śledziewski D, editors. Proces doskonalenia treningu i walki sportowej (II) [The process of perfecting training and sports fight]. Warszawa: Wydawnictwo AWF; 2005, 180-183.

6. Sterkowicz S, Franchini E. Techniques used by judoists during the world and Olympic tournaments 1995-1999. Human Movement 2000;2:24-32.

7. Otaki T. Inquiry. JU-DO Magazines of the Ko-do-Kan 1954;4(2):45-65.

8. Thibult C. Efficiency of Japanese Combats. JUDO Magazine of the Kodokan 1963;2:61-66.

9. Nakamura I, Tanabe Y, Nanjo M, Narazaki N. Analysis of winning points in World Senior Championships from 1995 to 1999. Bulletin of the Association for the Scientific Studies on Judo. Kodokan Report 2002;9:147-156.

10. Nakamura I, Yamaguchi K, Shigeoka T, Hamada H, Takeuchi Y. Comparison of Performance between Male and Female in 2003 World Judo championships. Bulletin of the Association for the Scientific Studies on Judo. Kodokan Report 2005;10:77-85.

11. Suganami M, Hirose N, Nakamura M, Maekawa N. A Study of lost competitions of Japanese male judo players at Europe. A Tournaments. Bulletin of the Association for the Scientific Studies on Judo. Kodokan Report 2001;9:1321.

12. Hamana J, Nose S, Sakai K, Suzuki W, Tanaka M. Analytical study of judo competitors. Bulletin of the Association for the Scientific Studies on Judo. Kodokan Report 1994;7:73-93.

13. Lipoński W. Encyklopedia sportów świata [in Polish] [The encyclopaedia of world's sports]. Poznań: Oficyna Wydawnicza Atena; 2008.

14. Adam M, Smaruj M, Tyszkowski S: The diagnosis of the technical-tactical preparation of judo competitors during the World Champions (2009 and 2010) in the light of the new judo sport rules. Archives of Budo 2011;(7):5-9.

15. Tomiki K. The fundamental principles of judo. Tokyo: Kodokan; 1956.

16. Pedro J, Turbin W. Judo techniques \& tactics. Champaign III.: Human Kinetics Publishers; 2001. 